\title{
SHOULD VIETNAMESE FIRM'S STOCKS BE LISTED IN A MSCI GLOBAL EQUITY INDEX? EXPERIENCE DRAWN FROM THE SAMPLE OF 30 COUNTRIES
}

\author{
Vo Hong Duc ${ }^{1}$, Doan Bao Huy ${ }^{2}$ \\ ${ }^{I}$ The Economic Regulation Authority, Australia \\ Ho Chi Minh City Open University, Vietnam \\ ${ }^{2}$ The University of New South Wales, Australia \\ Ho Chi Minh City Open University, Vietnam
}

(Received: 23/02/2014; Revised: 02/04/2014; Accepted: 16/06/2014)

\begin{abstract}
This study was conducted to investigate the argument of the increased co-movement between the
\end{abstract}

return of stocks, which are added to an MSCI Global Equity Index (MSCI Index) and the returns of the market index. It means that inclusion of the newly added stocks in an index leads to increased comovement between these stocks and the rest of the index. The MSCI Index is a broad and investable global equity benchmark and serve as the basis for over 500 exchange traded funds throughout the world. Our sample covers the MSCI Index inclusions from May 2003 to August 2008, corresponding to 16 adjustment quarters. Over this period, we have 1,274 index inclusion events over 46 countries in total. We found that inclusion into the MSCI Index leads to on average a higher beta with the national index. 21

out of the 30 countries in our sample experienced an increase in beta in the post-inclusion period. Given

the two stock exchanges in Vietnam are young in terms of a number of years since establishment and a small size of the market by the international standard, caution is required when evidence from wellestablished and matured markets used in this study is drawn. Nevertheless, the implications for listed firms in Vietnam are that their stocks will be more frequently traded by various groups of investors as long as the stocks are listed with an MSCI index, including the powerful MSCI Frontier Markets Indexes of 26 countries in the world.

Keywords: MSCI Index, co-movements, national stock index, frontier markets, Vietnam. 


\section{Introduction}

Empirical studies on the effect of index change have documented two types of phenomena. The first one is the positive price effect of index inclusion. It is well established that stocks that are added to the Standard and Poor's (S\&P) 500 index

experience a positive, risk-adjusted return

of about 5\% (see Harris and Gurel, 1986; Shleifer, 1986; Dhillon and Johnson, 1991). Deleted stocks, on the other hand, experience a statistically significant, though generally small drop in returns (see Goetzmann and Garry, 1986; Harris and Gurel, 1985).

The second phenomenon associated with index inclusion is the increased

co-movement of the newly added stocks

with other constituents of national indices. This strand of studies initially focuses on the US market, such as Vijh (1994) and Barberis, Shleifer, and Wurgler (2005). In particular, Barberis et. al. (2005) used a bivariate regression test and find that stocks added to the S\&P 500, on average, experience an increase in their beta with the rest of the index and a decrease in their beta with the rest of the market. While the S\&P500 has commanded much attention in recent years, the index inclusion effect has also been studied in other US indices as

well as prominent non-US indices. These

include the Russell 2000 (Petajisto, 2003),
Nikkei 500 (Liu, 2000) and Nikkei 225 (Hanaeda and Saritam 2001). Greenwood and Sosner (2007) also study the Japanese market and Hacibedel (2007) examines inclusion in the MSCI Emerging Markets Index. Claessens and Yafeh (2012) have

documented this increased co-movement

for newly added stocks with national indices using a comprehensive international dataset covering over 2000

additions in 40 countries and over 10-year

period.

In this paper, we propose to

investigate the increased co-movement

between the return of stocks, which are added to an MSCI Global Equity Index (MSCI Index) and the returns of the market index. It means that inclusion of the newly added stocks in an index leads to increased co-movement between these stocks and the rest of the index. Following this Introduction, Section 2 of the paper presents briefly related theories to possible set ground for the above argument. In Section 3, we will discuss our methodology and present the data and empirical results. Section 4 concludes.

\section{Brief discussions on related theories}

Various theories have been proposed to explain why inclusion of the newly added stocks in an index leads to increased co-movement between these stocks and the rest of the index. 
Under the traditional view with frictionless market and rational investors,

co-movement between the prices or returns

of stocks must come from the comovement between their future cash flows (or their fundamental values), since price is equal to the sum of discounted future cash flows (Barberis, Shleifer, \& Wurgler, 2005). Further, assuming that the market is efficient, any news that may affect firms' future cash flows will be reflected in the price immediately, and therefore the information environment should not have

any impact on the co-movement. This theory, however, cannot explain the widely-observed increased co-movement

post-inclusion between newly added stocks

and market indices because being included in a stock index is not supposed to change the covariance between the fundamental value of the stock and that of the index. Most national indices, like S\&P 500, select the constituents with a goal to reflect the

condition of the economy (or a sub-section

of the economy), rather than to measure the performance of individual stocks.

Another broad class of theories departs from the traditional assumptions and attempts to use the friction of market and irrationality of investors to explain the

increased co-movement. By relaxing

traditional assumptions, the co-movement

in price (return) is detached from the

co-movement of fundamental values.

There are three main views of those alternative theories (Barberis, Shleifer, \& Wurgler, 2005).

The first one is the category view where investors are believed to allocate investment into different categories, such as big stocks, and then choose specific stocks within the category. The second view is the habitat argument, which proposes that investors only invest into a

sub-set of all stocks available, known as

their "habitat".

Those two views can potentially

explain the increased co-movement

because the market index is a natural category or habitat for many investors, particularly large investment funds. The flow of funds those investors put into and take out of the index can induce common 
movement in the price (return) of stocks in the index.

The last theory is the information diffusion view, which argues that the market is not informational efficient and stocks incorporate information at different speed. In the context of index inclusion, the stocks in the index may adjust to information faster than those stocks not in the index, as the former tend to be more

well-known or have more analysts

following. For example, Kaul Mehrotra and Morck (2000) find that being added to an index results in improved transparency of a stock, thereby increasing its popularity. The different rates of information incorporation may lead to

different levels of co-movement between

fundamental values, as the changes in fundamental value are conveyed to investors through the diffusion of information. Under this view, stocks that adjust to information at the same rate tend

to co-move more strongly than that

between stocks incorporating information at different speed.

\section{Results}

3. Methodology, Data and Empirical

\subsection{MSCI Index Inclusion Sample}

In this study, we provide further evidence on the increased co-movement

between the return of stocks added to an index and the returns of the market index by examining the additions to the MSCI Global Equity Index (MSCI Index). The MSCI Index is a broad and investable global equity benchmark. It has been increasingly used for measuring the performance of growing numbers of global portfolios and is tracked by numerous Exchange Traded Funds (ETFs) (MSCI, 2013). Therefore, it becomes the natural habitat or category for many investors under the alternative theories.

Specifically, we examine the

co-movement of the returns of stocks being

added to the MSCI Index and the returns of national indices. If we find similar increase

in the co-movement, then the findings would be more likely to support the

friction- or sentiment-based theories of

co-movement. This is because being added

to the MSCI Index will make a stock part of the habitat or category of certain investors, particularly those large financial institutions, including pension funds, investment funds, and banks. For those 
investors, it is highly likely that the national indices are also their habitat or categories, especially for those who also track the national index performance. Therefore, the trading of those investors will cause the newly added stocks to

co-move more strongly with national

indices.

Further, the information-diffusion

argument may also fit into the context. Once a stock has been added to the MSCI Index, the speed at which it adjusts to news is expended to increase, converging to the speed of those stocks that are in the national indices. Therefore, the

co-movement between the added stock and

the national indices could increase.

For those stocks that have been included in the MSCI Index, we first attempt to explore whether there is any change in their beta, which is defined as

the co-movement of a stock's return with

the national stock index return. The chosen national stock indices are those most widely used for each country and are deemed as important indicators of the performance of the national stock market. We list the national indices chosen in this study in Table 1.

Our sample covers the MSCI Index inclusions from May 2003 to August 2008, corresponding to 16 adjustment quarters. We have obtained the information from the MSCI website under the section of Index Review. The MSCI Index has a few advantages for our study. Firstly, unlike many other national indices, MSCI Index have fixed and consistent quarterly index adjustments dates, which enable our study to use consistent time span to calculate relevant statistics for each inclusion event. Further, the composition of the MSCI Index is aimed at effectively representing the economy of each country and in the meantime ensures the investability of the stocks included in the index. As a result, a growing number of global portfolios and exchange traded funds (ETF) products are tracking the index and the index has, therefore, become the natural "habitat" or "category" for more and more investors.

Over this period, we have 1,274 index inclusion events over 46 countries in total. For some countries, however, there are only few observations. We decided to include only countries that have at least 10

observations in the sample. This cut-off

threshold is somewhat arbitrary and chosen to obtain relatively more accurate estimate of the index inclusion effect for each country. We further deleted those observations that have been added to MSCI Index and then deleted within one year. Finally, we checked whether we have the firm specific information from Datastream and excluded those firms that we cannot obtain reliable price or accounting data. This procedure provides the final data we employed in this study and we have summarized the composition of the sample in Table 1. In total, we have 1,157 observations over 30 countries. As 
expected, there are generally more For small capital markets, we have observations for countries with developed relatively fewer observations, such as capital markets, such as USA and Japan, Netherlands (10), Mexico (10), Italy (11) and large capital markets, such as China. and Turkey (11). 
Table 1. Composition of the Sample

\begin{tabular}{|c|c|c|}
\hline Country & Index & Number of Inclusions \\
\hline AUSTRALIA & AS $\times 200$ & 31 \\
\hline BRAZIL & IBOV & 32 \\
\hline CANADA & S\&P/TSX composite & 49 \\
\hline CHINA & HAND SENG CHINA ENTERPRISES & 66 \\
\hline EGYPT & EGYPT HERMES FINANCIAL & 14 \\
\hline FRANCE & FRANCE CAC 40 & 29 \\
\hline GERMANY & DAX 30 & 23 \\
\hline HONG KONG & HAND SENG CHINA ENTERPRISES & 25 \\
\hline INDIA & S\&P BSE (1000) National & 35 \\
\hline INDONESIA & IDX COMPOSITE & 12 \\
\hline ISRAEL & ISRAEL TA 100 & 17 \\
\hline ITALY & FTSEMIB & 11 \\
\hline JAPAN & NIKKI 225 & 131 \\
\hline KOREA & KOSPI & 50 \\
\hline MALAYSIA & FTSE MALAYSIA & 21 \\
\hline MEXICO & MEXICO IPC & 10 \\
\hline NETHERLANDS & AEX & 10 \\
\hline NORWAY & OSLO EXCHANGE & 12 \\
\hline POLAND & WARSAW GENERAL INDEX & 15 \\
\hline RUSSIA & RUSSIAN RTS INDEX & 22 \\
\hline SINGAPORE & STRAITS TIMES INDEX & 13 \\
\hline SOUTH AFRICA & FTSE/JSE AII SHARES & 23 \\
\hline SPAIN & MADRAID SE GENERAL & 17 \\
\hline SWEDEN & OMX STOCHOLM & 17 \\
\hline SWITZERLAND & SWISS Market SMI & 12 \\
\hline TAIWAN & TAIWAN SE WEIGHED TAIEX & 62 \\
\hline THAILAND & BANGKOK S.E.T. & 24 \\
\hline TURKEY & BIST NATIONAL 100 & 11 \\
\hline UNITED KINGDOM & FTSE 100 & 43 \\
\hline USA & S\&P 500 & 320 \\
\hline
\end{tabular}

\subsection{Pre- and Post-Beta Calculation}

In order to calculate the beta of each stock before and after the inclusion, we first collect the daily price data for all the included stocks and the national indices in Table 1 from Datastream. With the price data, we can then calculate daily returns, with which we can obtain estimates of beta for each stock. Specifically, for

pre-inclusion beta, we use daily returns of

each stock over one year period ending 30 days before the announcement date and the corresponding daily returns of the national index. For example, when an American company was included in the MSCI Index on the $15^{\text {th }}$ May 2004, we would then use its daily return from $15^{\text {th }}$ April 2003 to $15^{\text {th }}$ April 2004 and the daily return of the S\&P500 Index during the same period to calculate the stock's beta. We exclude the 30 daily observations before the inclusion date primarily because over this period, there might be information leakage about the inclusion (Claessens \& Yafeh, 2012). Another reason is that there is normally a

15-day lapse between the announcement

date and the effective date of index adjustment, and it is not clear whether this

period should be viewed as pre-inclusion 
or after-inclusion period (Lynch and Mendenhall, 1997). As a result, we exclude the observations 30 days before the announcement day to ensure that we have

an estimate of the pre-inclusion beta which

is unaffected by the inclusion announcement. With the stock and index returns, we run the following regression ${ }^{1}$ to

calculate the pre-inclusion beta:

$$
R_{i, j, \tau}=\alpha_{i, j, \tau}+\beta_{p, z} R_{M, j, \tau}+e_{i, j, t}
$$

where the subscript $i=1,2, \ldots, 1157$ represents the observations, $j=1,2, \ldots, 30$ the countries and $t=1,2, \ldots$ the date. $R_{i, j, t}$ is the tth daily return of the ith stock (of the $j$ th country) and $R_{M, j, t}$ is the tth daily return of the national index of country $j . e_{i, j, t}$ is the error term. We can obtain an estimate of $\beta_{\text {pre }}$ for each event stock, $\hat{\beta}_{\text {pres }}$.

We use the market model rather than CAPM to calculate the beta in pre- and post- inclusion. Mackinlay (1997) mentions that the validity of the restrictions imposed by the CAPM on the market model is questionable. Thus, there is a possibility that the results may be sensitive to the specific CAPM restrictions. By using the market model, this potential problem can be avoided. Similarly, we use the daily returns over one year, starting from one month after the inclusion, to calculate the post-inclusion beta with the same regression specification as for the pre-inclusion beta:

$$
R_{i, j, z}=\alpha_{i, j, z}+\beta_{\text {post }} R_{M, j, t}+e_{i, j, t^{\prime}}
$$

We decided to calculate

post-inclusion beta using daily return

starting 30 days after the inclusion date because previous research has documented substantial short term price and liquidity effect after a stock has been included in an index, see for example Shleifer (1986) and Eliott et al (2006). In other words, the month right after the inclusion may give us a noisy estimate of beta and thus we exclude this period in our estimation.

Another important measure of the

strength of the co-movement of stock

return with national index return is the coefficient of determination or $\mathrm{R}$ squared $\left(R^{2}\right)$ of the linear regression models (1) and (2). It measures the proportion of variability in the stock return that can be explained by the variability in the return of the nation index. We also record this measure from the regression for each of the event in our sample. In Table 2, we provide the summary statistics of the estimated betas and the $R^{2}$ of the regression. 


\section{Table 2. Pre-and Post-inclusion Beta and $\boldsymbol{R}^{2}$}

\begin{tabular}{|c|c|c|c|c|c|c|}
\hline Variables & Definition & Mean & Std Dev & $25 \%$ & Median & $75 \%$ \\
\hline $\begin{array}{l}\text { Pre-inclusion daily } \\
\text { Beta }\end{array}$ & $\begin{array}{l}\text { Beta calcuated using daily data for } 12 \\
\text { month (or the earliest day when data } \\
\text { available) ending } 30 \text { days prior to the } \\
\text { inclusi on date(Datastream) }\end{array}$ & 0.914 & 0.441 & 0.597 & 0.890 & 1.180 \\
\hline $\begin{array}{l}\text { Post-inclusion daily } \\
\text { Beta }\end{array}$ & $\begin{array}{l}\text { Beta calcuated using daily data for the } \\
12 \text { months starting } 30 \text { days after the } \\
\text { inclusi on date(Datastream) }\end{array}$ & 0.971 & 0.428 & 0.665 & 0.944 & 1.235 \\
\hline $\begin{array}{l}\text { Pre-inclusion daily } \\
R^{\wedge} 2\end{array}$ & $\begin{array}{l}\mathrm{R}^{\wedge} 2 \text { in the regression in calculating the } \\
\text { pre-inclusion Beta (Datastream) }\end{array}$ & 0.221 & 0.148 & 0.109 & 0.196 & 0.306 \\
\hline $\begin{array}{l}\text { post-inclusion daily } \\
R^{\wedge} 2\end{array}$ & $\begin{array}{l}\mathrm{R}^{\wedge} 2 \text { in the regression in calculating the } \\
\text { post-inclusion Beta (Datastream) }\end{array}$ & 0.273 & 0.170 & 0.139 & 0.249 & 0.385 \\
\hline
\end{tabular}

We find that the post-inclusion betas

co-movement of the stock return with its

national index return.

are higher than the pre-inclusion betas in

To further examine the inclusion effect, we have calculated the average

terms of mean, median, 25 percentile and changes in beta and changes in $R^{2}$ by 75 percentile values. This gives evidence that, on average, being included into the MSCI Index indeed lifts the beta of the included stocks with national indices. Further, the $R^{2}$ of the regression for

post-inclusion beta is higher than that of

from the post-inclusion estimates for all

events in each country and summarized the average changes in Table 3. The the regression for pre-inclusion beta. This significance of the change is obtained by running a regression with the change in beta (or $R^{z}$ ) as the dependent variable and finding again indicates that inclusion into the country's dummies as the explanatory 
variables. Out of the 30 countries we consider, stocks in 21 countries on average experience an increase in beta after the inclusion, though the increase is only statistically significant for four countries. In terms of $R^{2}$, the regression for stocks in 28 out of 30 countries produces higher $R^{*}$ after the inclusion (positive change in $R^{\mathbf{2}}$ ) and 17 average changes are statistically significant at least at 5 per cent significance level.

Overall, our results suggest that there is considerable increase in the

co-movement between the returns of the

stocks that have been added to the MSCI Index and national stock indices. On the one hand, these increases cannot be explained easily by the traditional view of co-movement since inclusion into MSCI

Index is unlikely to be related with the change in the fundamental value of a company. However, our finding is consistent with the habitat or category

views of the co-movement.

When included into the MSCI Index, the stock naturally enters into the habitat or category of some investors, particularly large financial institutions that track the MSCI Index. If those institutions also regard the national index as their habitat or category, their flow of funds into and out of their habitat and category may well increase the co-movement between the stock return and the return of the national index. 
Table 3. Average Changes in Beta and $\boldsymbol{R}^{2}$ for Each Country

\begin{tabular}{|c|c|c|}
\hline Country & $\begin{array}{l}\text { Average Change in } \\
\text { Beta }\end{array}$ & $\begin{array}{l}\text { Average Change in } \\
\text { Rn2 }\end{array}$ \\
\hline AUSTRALIA & 0.0361 & $0.0363 *$ \\
\hline BRAZIL & $0.2213 * * *$ & $0.1565 * * *$ \\
\hline CANADA & 0.0198 & $0.0575 * * *$ \\
\hline CHINA & -0.0240 & $0.0703 * * *$ \\
\hline EGYPT & 0.1230 & 0.0588 \\
\hline FRANCE & $0.1091 * *$ & $0.0823 * * *$ \\
\hline GERMANY & 0. $1561 *$ & $0.1004 * * *$ \\
\hline HONG KONG & -0.0485 & $0.0546 * * *$ \\
\hline INDIA & 0.0994 & $0.1280 * * *$ \\
\hline INDONESIA & -0.0482 & 0.0328 \\
\hline ISRAEL & -0.0609 & -0.0400 \\
\hline ITALY & -0.0420 & 0.0441 \\
\hline JAPAN & 0.0259 & $0.0608 * * *$ \\
\hline KOREA & 0.0657 & $0.0779 * * *$ \\
\hline MALAYSIA & -0.0679 & 0.0294 \\
\hline MEXICO & 0.1166 & $0.1491 * * *$ \\
\hline NETHERLANDS & -0.0063 & 0.0114 \\
\hline NORWAY & -0.0211 & $0.1327 * * *$ \\
\hline POLAND & 0.1095 & $0.0784 * *$ \\
\hline RUSSIA & 0.0881 & $0.1245 * * *$ \\
\hline SINGAPORE & 0.1143 & $0.0966 * *$ \\
\hline SOUTH AFRICA & $0.1659 * * *$ & $0.0791 * * *$ \\
\hline SPAIN & 0.0826 & 0.0339 \\
\hline SWEDEN & -0.0537 & 0.0011 \\
\hline SWITZERLAND & -0.0813 & -0.0099 \\
\hline TAIWAN & 0.0384 & $0.0393 * *$ \\
\hline THAILAND & 0.0287 & 0.0174 \\
\hline TURKEY & 0.1854 & $0.0697 *$ \\
\hline UNITED KINGDOM & 0.0990 & 0.0083 \\
\hline USA & $0.0818 * *$ & $0.0224 * *$ \\
\hline Total Average & 0.051 & 0.0600 \\
\hline
\end{tabular}

Note: The significance levels are: *** 1\%, **5\% and *10\%. The significance of the estimates is obtained by running a regression with the change in beta (or $R^{2}$ ) as the dependent variable and the country dummies as the explanatory variables.

3.3 Determinants of Changes in Co- French 1992). We use total asset of a movement

If a firm's behaviour and performance remain relatively unchanged after being included in the MSCI, then what factors explain the magnitude (the absolute value) of the change in the beta and $R^{2}$ that we have observed in the previous section? Existing literature and intuition suggest the following candidates, whose significance will be tested in a regression analysis in this section.

The first group of candidates are firm specific factors and the rationale is that certain firm characteristics have long been found to be related with the beta of the firm's stock, (see for example, Fama \&

newly-added firm to approximate the size of the firm and examine whether the change in co-movement is systematically different for big and small firms. Firm leverage, defined as the net debt of a firm divided by its total asset, is also examined. 
More importantly, the pre-inclusion beta

and its squared value are proposed in our study as explanatory variables (Claessens \& Yafeh, 2012). The justification for

pre-inclusion beta is that its level represents

the pre-inclusion risk of a stock and the

inclusion effect may well be different for stocks of different levels of risk. We include the squared value of the

pre-inclusion beta as we suspect the impact

of pre-inclusion beta may be nonlinear. We

obtained the accounting data from Datastream and the summary statistics and explanations of the variables are provided in Panel A of Table 4.

Another group of factors are related to the country specific characteristics. The per capita GDP in US dollar may be regarded as a measure of the level of economic development of a country. The market capitalisation of the stock market over GDP is a proxy for the size of the stock market of a country. These two factors are important because, to a large extent, they reflect the stage of the development of a country's financial market and the economy. The index inclusion effect of stocks in a developed economy and mature financial market could be different from that of stocks in a

less-developed market with a small

financial market. Panel B of Table 4 presents the explanation and summary statistics of the country specific data. We have obtained the data from the World Bank and for each sample event, we use the country specific data in the year of its inclusion. World Bank does not have information for Taiwan as it is included within China. We have collected its GDP and market capitalization data from the Taiwan Statistics Office and Taiwan Stock Exchange.

Finally, we also include a time trend in the regression since we expect that the

index-inclusion effect could change over

time (Barberis, Shleifer, \& Wurgler, 2005). One force that drives the trend may be the increasing popularity of MSCI Index, which means that being added to the MSCI Index can make a stock a natural habitat or category increase a number of investors over time. Table 5 presents the Pearson Correlation Coefficients of the explanatory variables used in our study, with the

$\mathrm{p}$-value of estimates in the parenthesis. As we can see, expect for the correlation 
correlations are generally low and mostly insignificant. In the regression analysis, we

between pre-beta and its squared, the other did not run into any multicollinearity issue.

Table 4. Firm and Country Specific Variables

\begin{tabular}{|c|c|c|c|c|c|c|}
\hline \multicolumn{7}{|c|}{ Panel A: Firm specific data } \\
\hline Variables & Definition & Mean & Std Dev & $25 \%$ & Median & $75 \%$ \\
\hline Total Assets & $\begin{array}{l}\text { Total firm assets in billion US } \\
\text { dollars, three months before } \\
\text { the inclusion data } \\
\text { (Datastream) }\end{array}$ & 12.21 & 44.53 & 1.11 & 2.59 & 6.77 \\
\hline Firm Leverage & $\begin{array}{l}\text { Total debt to total assets, } \\
\text { three months before the } \\
\text { inclusion data (Datastream) }\end{array}$ & 0.105 & 0.286 & -0.049 & 0.130 & 0.280 \\
\hline \multicolumn{7}{|c|}{ Panel B: Country Specific Data } \\
\hline $\begin{array}{l}\text { GDP per capita (in the } \\
\text { year of inclusion for } \\
\text { each company) }\end{array}$ & $\begin{array}{l}\text { In Thousands US dollar } \\
\text { (World Bank) }\end{array}$ & 28,301 & 16,478 & 13,693 & 34,102 & 40,292 \\
\hline $\begin{array}{l}\text { Market } \\
\text { capitalisation/GDP (in } \\
\text { the year of inclusion } \\
\text { for each company) }\end{array}$ & Obtain data from World Bank & 120.36 & 70.35 & 82.55 & 123.09 & 138.36 \\
\hline
\end{tabular}


Table 5. Correlation Coefficients of Explanatory Variables

\begin{tabular}{lccccccc}
\hline Variables & GDP & MC/GDP & Pre-beta & Pre-beta^2 & Leverage & Total Asset \\
\hline GDP & 1 & & & & & \\
MC/GDP & - & & & & & \\
& 0.190 & 1 & & & & \\
Pre-beta & 0.000 & - & & & & \\
& 0.124 & 0.019 & 1 & & & \\
Pre-beta^2 & 0.000 & 0.520 & - & & & \\
& 0.113 & 0.027 & 0.926 & 1 & & \\
Leverage & 0.000 & 0.363 & - & - & & \\
& 0.048 & -0.037 & -0.119 & -0.113 & 1 & & \\
Total Asset & 0.101 & 0.212 & 0.000 & 0.000 & - & & \\
& 0.089 & -0.026 & 0.013 & -0.007 & 0.109 & 1 & \\
Time Trend & 0.002 & 0.374 & 0.667 & 0.818 & 0.000 & - & \\
& 0.038 & 0.080 & 0.139 & 0.094 & -0.045 & 0.113 & 1 \\
& 0.201 & 0.006 & 0.000 & 0.001 & 0.130 & 0.000 & - \\
\hline
\end{tabular}

The regression model to examine the absolute change in beta and $\mathrm{R}$ squared is specified as below and we estimate using OLS with standard errors clustered by country.

$$
\left|\Delta \beta_{i, j, Y)}\right|\left(\operatorname{or}\left|\Delta R_{i,(j, Y)}^{2}\right|\right)=\alpha_{i}+\beta_{1} T+\beta_{3} G D P_{j, Y}+\beta_{3}\left(\left[\frac{M C}{G D P}\right)\right]_{j, Y}+\beta_{4} P_{r}-b e t a_{i}+\beta_{4} P_{r e}-1
$$

where the $\left|\Delta \beta_{i, j, n)}\right|\left(\left|\Delta R_{i,(j, Y)}^{z}\right|\right)$ represents the absolute change in the beta $\left(R^{2}\right)$ of stock $i$. The other subscripts $j$ and $Y$ identify the country of the stock and the event year of the inclusion respectively. Note these two subscripts do not represent a panel-data setting, as multi-subscripts normally do, rather they simply act as indicators for us to identify the per capita GDP, $G D P_{j, Y}$ and market capitalisation over GDP, $\left(\left[\frac{M C}{G D P}\right)\right]_{j, Y}$, for the $j$ th country in the $Y$ th year. $T$ is the time trend for the 16 quarters in our sample. The rest of the variables are self-explanatory and firm-specific, indicated by the subscript $i$.

Econometrically, our specifications of $G D P_{j, Y}$ and $\left.\left(-\frac{M C}{G D P}\right)\right]_{j, Y}$, , deviate from the standard cross-sectional setting, because these two measures have both cross-sectional and time-dependent variation. We could have used static measures of those two variables, such as the values in a particular year, so that we have only cross-sectional variation. This is the methodology used by Claessens \& Yafeh (2012). However, if one checks the annual GDP of each country (Appendix 1) and market cap over GDP (Appendix 2), substantial variations over time are observed. Therefore, we believe static measures are inappropriate for our study and the information contained in the time variation justifies our specification. As a robustness check, we run a regression using GDP and market cap over GDP in 2003 for all stocks and the results remain qualitatively consistent (Appendix 3).

The estimated coefficients are presented in Table 6. For the change in beta, we find that country characteristics, firm leverage and total asset are not 
significant in explaining the absolute

changes. However, the pre-inclusion beta

pre-inclusion beta, the bigger the change in

and its squared terms are highly significant, both statistically and economically, despite the fact that they are highly correlated with each other (with a correlation coefficient $>0.9$, Table 5). The sign of the estimates on the two terms indicate a nonlinear marginal effect of the

beta. The marginal effect of pre-inclusion

beta on the change in beta follows a parabola with the vertex at the point $\beta \approx$ 0.875 . This suggests that stock with either

pre-inclusion beta on the change in beta

very low or very high pre-inclusion beta

tend to experience a large change in

after the inclusion: when the pre-beta is

post-implementation beta relative to the

less than 0.875 , the higher the

pre-inclusion beta, the smaller the change

ones whose beta is in the middle of the distribution.

in beta and when the pre-inclusion beta is higher than 0.875, the higher the

Table 6. Regression Analysis of Index-inclusion Effects 


\begin{tabular}{lcc}
\hline & $\begin{array}{c}\text { Absolute change } \\
\text { in daily } \boldsymbol{\beta}\end{array}$ & $\begin{array}{c}\text { Absolute change } \\
\text { in daily R squared }\end{array}$ \\
\hline Constant & $0.4335^{* * *}$ & $0.1127^{* * *}$ \\
Time trend & 0.0472 & 0.0121 \\
Per capita GDP & 0.0006 & $0.0059^{* * *}$ \\
Market capitalisation/GDP & 0.0022 & 0.0005 \\
Pre-inclusion beta & -0.0007 & -0.0005 \\
Pre-inclusion beta squared & 0.0005 & 0.0003 \\
Firm leverage & -0.0015 & $-0.0132^{* * *}$ \\
Firm total assets & 0.0097 & 0.0040 \\
& $-0.4337^{*} * *$ & -0.0170 \\
R squared & 0.0574 & 0.0265 \\
& $0.2475 * * *$ & 0.0099 \\
& 0.0266 & 0.0148 \\
& -0.0119 & 0.0054 \\
& 0.0302 & 0.0115 \\
& -0.00003 & 0.0001 \\
& 0.00019 & 0.0001 \\
& 0.1664 & 0.0938 \\
\hline
\end{tabular}

Note: The dependent variables are the absolute values of the change in daily beta or in daily $R$ squared. Explanatory variables include preinclusion beta (daily), pre-inclusion beta squared, a time trend, per capita GDP, the ratio of market capitalization to GDP, firm leverage (Net Debt to Total Asset) and Total Assets. Regressions are OLS with standard errors clustered by country below the estimates. ***, ** and $*$ denote coefficients significant at the 1,5 and 10 percent, respectively.

We have run regressions with alternative specifications. When we do not

include the squared pre-inclusion beta, the

the cubed term of pre-inclusion beta, its

coefficient is not significant (see Appendix 5). Therefore we conclude that the level

pre-inclusion beta is still significant, but and squared term of pre-inclusion beta is

the $\mathrm{R}$ squared of that regression was only 0.026 (see Appendix 4), which again suggests the importance of this squared term in explaining the change in beta. If necessary and sufficient in the specifications. For the change in $R^{2}$, the time trend is statistically significant but of limited economic impact. This indicates that on average, the strength of the 
co-movement between the newly added

stocks and national indices is slightly increasing over time. This is consistent with the fact that the MSCI Index are gaining popularity over time and become the natural "habitat" or "category" for more investors. The limited size of the estimate could be due to the fact that our data only spans for 5 year. To observe significant time trend, longer time period sample is probably required. In addition, the market cap over GDP has significant negative effect on the change in $R^{z}$. This

means that the index-inclusion effect is

small for stocks in more developed capital markets.

\section{Implications for Vietnam's listed firms}

In Vietnam, prior to the establishment of the national stock exchanges, there has been a debate on an appropriate model. Until July 1998, the Prime Minister finally approved for the establishment of two separate exchanges: one in Ho Chi Minh City, known as Ho Chi Minh City Stock Exchange (HOSE) which was officially launched in July 2000 (renamed in 2007) and the other in Ha Noi, known as Ha Noi Stock Exchange 9HNX) which was launched 5 years after, in 2005 (renamed in 2009). Both exchanges are operated on a model of one stakeholder owned company with 100 per cent State ownership of 1,000 billion Vietnam Dong (VND).

Currently there are more than 300 stocks listed in HOSE and almost 400 stocks listed in HNX. Stocks listed in each of these exchanges are required to follow different sets of rules in terms of: (i) conditions for listing; (ii) trading approach; (iii) funds' certificates; and (iv) price's margins. For example, one of the conditions to be listed in the HOSE is that the company must have a book value of VND80 billions or more at the time of listing whereas for the HNX, this condition is as low as VND10 billions.

In this paper, we have examined the

co-movement between the returns of stocks

added to the MSCI Global Equity Index and the returns on the national index. We conclude with a general discussion of methods and results. The first step was the identification and collection of MSCI Index inclusions from May 2003 to August 2008. An initial sample of 1.274 additions over 46 countries was collected. To prepare the data, we excluded securities without reliable pricing data, those added and deleted from the index within a 12 month period and countries with insufficient number of observations. The final data set contained 1157 observations from 30 countries.

To measure whether changes in

co-movement occur after being added to

the MSCI Index, two OLS regressions were conducted, with OLS (1) and (2)

estimating the pre and post-inclusion betas

respectively. The explanatory power of the models are measured using the coefficient of determination $R^{2}$, and we regard this statistic as an additional measure of the 
co-movement between the newly added

stock and the national indices.

We found that inclusion into the MSCI Index leads to on average a higher beta with the national index. 21 out of the 30 countries in our sample experienced an

increase in beta in the post-inclusion

period. However, the result may not be conclusive, since only 4 countries had statistically significant increase. The results on $R^{2}$ are more powerful since 28 of the 30 countries produced higher $R^{2}$ after the inclusion. 17 changes are statistically significant at the 5 percent level.

We argue that our findings are more

likely to be consistent with the friction- or

sentiment-based view of co-movement,

which has been analysed by BSW (2005). Being added to the MSCI Index makes a stock part of the habitat or category for certain groups of investors, and the trading of those investors drives the increase in the

co-movement. The information diffusion

argument can also potentially explain our results, since the inclusion may have improved the information environment of the included stock to a level similar to that of stocks in the national indices.

To examine what factors explain the magnitude of the change in beta and $R^{2}$, we reviewed the existing literature as our starting point for the development of a regression model. We have done this to ensure that the model has a sound underlying economic basis, as well as being intuitively appealing. The factors selected can be grouped into firm and country explanatory variables. We found that country characteristics, firm leverage and total assets are not significant in explaining the absolute change in

post-inclusion beta. However, we did find

that the pre-inclusion beta and its squared

term were both statistically and economically significant, indicating a nonlinear marginal effect of the

pre-inclusion beta on the change in beta.

The time trend and the size of the stock market of a country are found to be significant in explaining the change in the $R^{2}$.

Given the two stock exchanges in Vietnam are young in terms of a number of years since establishment and a small size of the market by the international standard, caution is required when evidence from well-established and matured markets is drawn. Nevertheless, the implications for listed firms in Vietnam are that their stocks 
will be more frequently traded by various groups of investors as long as the stocks are listed with an MSCI index, including the powerful MSCI Frontier Markets Indexes of 26 countries in the world. 


\section{REFERENCES}

Barberis, N., Shleifer, A., and Wurgler, J. 2005 Co-movement, Journal of Financial Economics 75, 283-317.

Claessens, S and Yafeh, Y.,2012. Co-movement of newly added stocks with national

market indices: evidence from around the world, Review of Finance 17, 203-227.

Dhillon, Upinder, and Herb Johnson, 1991, Changes in the Standard and Poor's 500 list, Journal of Business 64, 75-85.

Eliott, W., Van Ness, B., Walker, M., Warr, R., 2006. What Drives the S\&P 500 Inclusion Effect? An Analytical Survey. Financial Management 35, 31-48.

Fama, E. F., \& French, K. R. (1993). Common risk factors in the returns on stocks and bonds. Journal of Financial Economics, 33(1), 3-56.

Goetzmann, W., Massa, M., 2003. Index funds and stock market growth. Journal of Business 76, 1-28.

Greenwood, R. and Sosner, N. 2007 Trading patterns and excess co-movement of stock returns, Financial Analysts Journal 63, 69-81.

Hacibedel, B., and Van Bommel, J., 2007. Do Emerging Markets Benefit from Index Inclusion? Money Macro and Finance Research Group Conference 2006; 128, Money Macro and Finance Research Group.

Hanaeda, H., \& Serita, T., 2003. Price and Volume Effects Associated with a Change in the Nikkei 225 Index List: new evidence from the big change on April 2000.

International Finance Review, 4, 199- 225.

Harris, L., Gurel, E., 1986. Price and volume effects associated with changes in the S\&P 500: new evidence for the existence of price pressure. Journal of Finance 41, 851860.

Kaul, A., Mehrotra, V., Morck, R., 2000. Demand curves for stocks do slope down: new evidence from an index weights adjustment. Journal of Finance 55, 893-912.

Liu, S., 2000. Changes in the Nikkei 500: New evidence for downward sloping demand

curves for stocks. International Review of Finance, 1(4), 245-267. 
Lynch, A., Mendenhall, R., 1997. New evidence on stock price effects associated with changes in the S\&P 500 index. Journal of Business 70, 351-383.

MSCI., 2013, MSCI All Country Indices. Retrieved from http://www.msci.com/products/indices/country_and_regional/all_country/

Petajisto, A., 2003. What makes demand curves for stocks slope down? MIT Working Paper

Shleifer, A., 1986. Do demand curves for stocks slope down? Journal of Finance 41, 579-590.

Vijh, A., 1994. S\&P 500 trading strategies and stock betas. Review of Financial Studies 7, 215-251. 